\title{
PROPOSTA DE IMPLEMENTAÇÃO DA FERRAMENTA INBOUND MARKETING: ESTUDO DE CASO NA EMPRESA GUERREIROS SOLUÇÕES GASTRONÔMICAS
}

\section{ARTIGO ORIGINAL}

CHAVES, Fernanda Klíssia de Souza ${ }^{1}$, SOUZA, Lucas Machado Menezes de ${ }^{2}$, SANTOS, Vinícius Nascimento 3 , ROBERTO, José Carlos Alves ${ }^{4}$

CHAVES, Fernanda Klíssia de Souza. Et al. Proposta de implementação da ferramenta Inbound Marketing: Estudo de caso na empresa Guerreiros Soluções Gastronômicas. Revista Científica Multidisciplinar Núcleo do Conhecimento. Ano. 06, Ed. 11, Vol. 12, pp. 154-175. Novembro de 2021. ISSN: 2448-0959, Link de acesso: https://www.nucleodoconhecimento.com.br/administracao/ferramenta-inbound, DOI: 10.32749/nucleodoconhecimento.com.br/administracao/ferramenta-inbound

\section{RESUMO}

O presente artigo visa apontar uma solução viável para o problema de marketing encontrado na Guerreiros Soluções Gastronômicas, empresa de pequeno porte que atua no segmento alimentício. Realizou-se na empresa um diagnóstico organizacional nas seis áreas funcionais, onde constatou-se, como resultado, a área de marketing como a de maiores índices de deficiência. Diante do exposto foi elaborado o seguinte problema de pesquisa: Como a implementação da ferramenta Inbound Marketing pode melhorar as vendas da empresa? Tem como objetivo geral o estudo da ferramenta mais adequada, nesse caso o Inbound Marketing, para solucionar problemas na área mais crítica da empresa. Esta é uma pesquisa com

\footnotetext{
${ }^{1}$ Graduando no curso de Administração.

${ }^{2}$ Graduando do curso de Administração.

${ }^{3}$ Graduando do curso de Administração.

${ }^{4}$ Orientador. Mestre em Engenharia de produção, Especialista Logística empresarial e Graduado em Administração com Ênfase em Marketing.
} 
fins explicativos, realizada por meio da pesquisa de campo para a análise dos dados coletados. Foi adotada a ferramenta de qualidade $5 \mathrm{~W} 2 \mathrm{H}$, como instrumento auxiliador de intervenção para o problema na organização, e foi proposta a aplicação do Inbound Marketing, que permite construir uma ligação entre colaborador e cliente e atingir seu público-alvo, por meio de mídias sociais e atrativos, e alavancar as vendas da empresa. Sendo assim, em conjunto com a introdução da ferramenta Inbound marketing, foram planejadas atividades de treinamento e capacitação dos colaboradores e mudanças estratégicas, apoiadas por uma consultoria externa, também foi calculado o investimento para aquisição de equipamento e contratação de colaborador dedicado para gestão das ações de marketing. O objetivo inicial deste estudo obteve êxito na realização da proposta interventiva para a empresa, e por isso, tendo em vista a aplicação da ferramenta Inbound no setor de marketing, a expectativa é de crescimento e aumento nas vendas da organização, pois, devido ao foco maior em propaganda e divulgação e do uso de maneira correta das mídias sociais, é possível agregar mais clientes e cativá-los, de forma que se tornem fiéis e sempre retornem para consumir cada vez mais.

Palavras-Chave: Marketing, Mídias Sociais, Inbound.

\section{INTRODUÇÃO}

Apresenta-se um estudo de caso realizado na empresa Guerreiro 's Soluções Gastronômicas, empresa de pequeno porte do ramo alimentício na região metropolitana de Manaus/Amazonas, que após diagnóstico organizacional, com base em dados levantados, foi verificada a deficiência no setor de marketing. Por esse motivo, sugeriu-se a proposta de implementação de uma ferramenta de análise no setor, sendo ela, o Inbound Marketing.

Em consequência do diagnóstico que se originou na empresa Guerreiros Soluções Gastronômicas, e após uma análise de dados dos fatores críticos das áreas funcionais existentes na empresa, foi possível observar que o setor de marketing obteve o menor índice de desempenho comparado às demais áreas da organização. 
Em decorrência disso, o objetivo geral deste artigo se resume ao estudo da ferramenta mais viável para eliminar as deficiências do setor de marketing na empresa, acarretando consequentemente no aumento das vendas da organização.

Para a empresa se manter viva no mercado, é necessário um bom relacionamento com o público. Segundo Chiavenato (2008, p. 216), "o cliente é imprescindível para a empresa se manter no mercado e o atendimento ao cliente é um dos aspectos de maior importância do negócio". Uma vez proposta uma ferramenta de intervenção para solução da problemática, é levantado o seguinte questionamento: Como a implementação da ferramenta Inbound Marketing pode melhorar as vendas da empresa?

Quanto à natureza da pesquisa, baseia-se na pesquisa quali-quantitativa, pois essa abordagem mescla pontos fortes dos dois tipos de análise. Quanto aos fins, foi utilizada a pesquisa explicativa. Quanto aos meios, foi realizada uma pesquisa de campo. E como método interventivo, foi utilizada a ferramenta $5 \mathrm{~W} 2 \mathrm{H}$.

A pesquisa e o Diagnóstico Organizacional permitiram uma maior compreensão do ambiente da empresa, e com base nas informações encontradas foi desenvolvido um objetivo específico: $O$ estudo da implementação da ferramenta Inbound Marketing, que visa solucionar o problema do setor.

Por fim, espera-se que com esta pesquisa, e após as técnicas aprendidas com o auxílio da aplicação da ferramenta Inbound Marketing, a empresa estudada obtenha lucros consideráveis com o aumento das vendas e fidelização dos seus clientes.

\section{FUNDAMENTAÇÃO TEÓRICA}

Este tópico refere-se aos estudos que abordam questões referentes as melhorias no setor de Marketing na empresa Guerreiros Soluções Gastronômicas. Após englobar uma série de análises feitas por outros autores, para novas sugestões de caminhos e propostas possíveis, foi possível observar detalhes indispensáveis para que essa evolução fosse viável.

RC: 101987

Disponível em:

https://www.nucleodoconhecimento.com.br/administracao/ferramenta-inbound 
Podemos discutir mais a fundo, por meio deste artigo, estratégias para a área de Marketing, que vem acompanhada de inovações. Para Kloter (2017), as mídias sociais têm um papel fundamental nessa nova era do marketing, sendo assim, essas ferramentas digitais serão também um meio de propagação do Marketing atual. Segundo Sant'Anna et al. (2013), por meio da publicidade é possível vender produtos, serviços e até mesmo ideias, de modo que sejam propagados.

Logo, entende-se que a publicidade também é uma ferramenta que o marketing utiliza para fundamentar suas estratégias.

\subsection{CONCEITO DE MARKETING}

A definição de Marketing possui variações e divergência de opiniões. O Marketing é, de fato, uma ciência, porém, o Marketing também é um processo, pois possui etapas para determinado fim. O Marketing também é uma arte, uma ferramenta, uma atividade, uma estratégia, enfim, seu conceito é algo altamente amplo.

Para Martins (2020), o conceito de Marketing está relacionado tanto à satisfação do cliente quanto à satisfação da empresa, visando um relacionamento de longo prazo entre eles. No entanto, para Mendes; Alberto (2015), o marketing é um meio de trazer lucratividade suprindo necessidades, quando bem utilizado por profissionais que possuem o devido treinamento para atingir objetivos desejados.

\subsubsection{FUNÇÕES DA ÁREA DE MARKETING}

Sendo o Marketing um conjunto de atividades técnicas e estratégias, assim como um dos setores mais importantes dentro de uma organização, o profissional de Marketing tem como objetivo usufruir desta ciência, utilizando táticas que o ajudem a conhecer e atrair os seus clientes, definindo-se assim um público alvo, o que também aumenta as expectativas de se tornarem clientes fiéis $e$, consequentemente, contribui para o aumento no número de vendas e para o crescimento na reputação da marca de determinada empresa. 
Em uma de suas obras, Kloter (2017) afirma que os profissionais de Marketing precisam estar suficientemente preparados para enfrentarem o mercado atual e prenderem a atenção de seu consumidor, uma vez que, quanto mais os anos passam e a tecnologia evolui, mais difícil se torna manter a atenção de um cliente, de maneira que sua marca precisa ser, de fato, surpreendente, para tornar-se digna de ser ouvida, defendida, fidelizada, de modo que se torne indispensável para o cliente e o faça retornar. Para Paula; Souza (2016), atualmente, e principalmente em tempos de crise, é dever de todo comerciante construir estratégias que fidelizem seus clientes e mantenha a consistência.

Sendo assim, fica ainda mais visível a importância que esta ciência possui dentro de uma empresa, uma vez que, por meio dela, clientes serão atraídos, chamados e fidelizados, o que são considerados os pontos mais importantes para se manter uma organização viva.

\subsubsection{MARKETING ESTRATÉGICO}

A abordagem do marketing estratégico é focada em resultados a longo prazo, pois baseia-se em decisões no presente e incita a busca contínua de melhorias e resultados, enquanto busca uma forma de atender as necessidades do mercado. No marketing estratégico, o cliente é o foco a ser conquistado. Com métodos e ferramentas, o marketing "moderno" analisa e entende os desejos e necessidades do consumidor, enquanto o estratégico direciona o produto/serviço de maior interesse para o consumidor, com base em suas pesquisas e preferências, apontadas pelo mercado. Conforme Mendes; Alberto (2015), o marketing estratégico precisa estar inserido no contexto adequado para a situação, visto que não há sentido em inserir um anúncio em um site que trata de um assunto totalmente diferente.

Segundo explica Isabelle (2009): 
As estratégias voltadas para o mercado permitem a empresa obter um desempenho superior, determinando competências diferenciadas e combinando valores dos clientes com as competências exigidas. O cliente passa a ser o ponto central de todas as operações da empresa que tem como lema a criação de valor para ele (ISABELLE, 2009, p. 14).

Conclui-se que o Marketing, como método estratégico, agrega valor para a organização, pois, por meio de alguns recursos, ele permite identificar e conhecer o seu público-alvo, assim como descobrir seus desejos e necessidades, o que, consequentemente, possibilita a fidelização cliente e reduz o risco de perdê-lo facilmente para o concorrente.

\subsubsection{MARKETING NO SÉCULO XXI}

O marketing no século XXI é voltado para o ambiente digital, um ambiente virtual voltado para o consumo de produtos/serviços a um clique de distância. Segundo Kotler (2009, p. 18), "à medida que o ritmo da mudança se acelera, as empresas não podem mais se basear nas antigas práticas empresariais para manter a prosperidade."

Há 60 anos, quando o marketing surgiu no Brasil, muitas propagandas e publicidades eram realizadas por meio de outdoors e placas em espaços públicos. No século XXI, as grandes placas e outdoors perderam espaço para uma máquina que cabe na palma da mão. Se antes havia grandes espaços físicos para a realização do marketing, hoje existem espaços ainda maiores no ambiente virtual, no qual o consumo é frenético e o marketing de produtos surge a todo instante, 24 horas por dia, todos os dias no ano. Porém, nem tudo é lucro, a disputa por clientes é acirrada pelas empresas e prevalece o marketing mais assertivo a respeito das necessidades do consumidor.

O marketing do século XXI utiliza ferramentas de pesquisa e algoritmos, de preferências, mídias sociais. Graças a essas tecnologias é possível prever os 
desejos e necessidades futuras do consumidor, o que faz com que o marketing moderno seja eficaz e eficiente. Essa praticidade encurtou a distância do produto até o cliente, de modo a promover ainda mais o consumo no conforto de sua própria residência. Fox; Rainie (2014) dizem que a necessidade de estar conectado ocorre não somente por consumidores, mas também pelo comércio. Um possui influência sobre o outro e estão interligados.

\subsubsection{INBOUND MARKETING}

O Inbound Marketing se trata de um mecanismo para publicidade e propaganda que auxilia as empresas a se promoverem por meios digitais, como sites, blogs, vídeos, entre outros, com a intenção de chamar a atenção dos consumidores. Ou seja, ela tem a função de inserir a empresa no meio digital e criar uma reputação que ajude a promover os seus produtos ou serviços.

Nascimento (2017) traz à tona a afirmação de que a Publicidade e a Propaganda estão vinculadas. Assim como Siqueira (2020) estabelece que, no meio online, a necessidade de ser atrativo é muito importante, o bastante para que seus clientes fixem o olhar e queiram adquirir aquele produto ou serviço.

Diferente dos modelos de marketing tradicionais, baseados em interrupções (marketing que tira atenção do consumidor), o Inbound Marketing é mais sutil, com anúncios menos invasivos e a partir do compartilhamento realizado pelos próprios clientes da marca. Dessa forma, o Inbound Marketing conquista a permissão de se comunicar, por meio do desenvolvimento de um relacionamento a longo prazo com o consumidor.

\subsubsection{MÍDIAS SOCIAIS}

Mídias Sociais são espaços ou estruturas voltados para a comunicação de pessoas ou empresas, e tais comunicações ocorrem de maneira pessoal ou profissional. Todos os dias, milhares de pessoas estão conectadas às redes sociais, consumindo 
algum tipo de produto ou serviço, o que torna esse ambiente um universo de possibilidades para o marketing atrativo. Para Santos; Andreoli (2015), as organizações passam por desafios significativos devido ao fluxo de movimentações que ocorrem na internet. Do ponto de vista organizacional, as redes sociais são a porta de entrada para um relacionamento com o consumidor, e isso permite o compartilhamento da visão empresarial, a interação direta ou indireta com o cliente, o conhecimento aprofundado do público, a criação de um ambiente controlado para a marca, informação em tempo real e possibilita a divulgação de empresas com baixo orçamento. $O$ ambiente virtual é um campo favorável e promissor para o nascimento de uma empresa no século XXI, afinal, estamos na era da tecnologia, e quanto mais os anos passam, mais ela avança e cresce. A tecnologia está em constante mudança e evolução, e com ela, novos meios de se empreender tem aparecido, assim como clientes ávidos para adquirir e consumir cada vez mais.

Segundo Kaplan; Haenlein (2012), conforme o passar do tempo, as empresas, em sua grande maioria, adotaram as mídias sociais como meio divulgação, desenvolvimento e aplicação de suas marcas.

\subsubsection{DESENVOLVIMENTO E APLICAÇÃO}

Para a aplicação do Inbound marketing é necessário desenvolvimento e amadurecimento de uma ideia, que posteriormente será passada para o consumidor. Segundo Gomes e Mesquita (2016), existem cinco aspectos importantes do Inbound Marketing, são eles: a produção de conteúdo, as características do conteúdo e o momento de entrega, o conhecimento dos clientes, a utilização de canais diversificados e a relação de produção e resultados. Segundo diferentes autores, o Inbound Marketing é a melhor maneira, atualmente, de conquistar consumidores. Mas como nem todos os consumidores são iguais, é importante saber conversar de forma diferente com cada um, em cada etapa do funil. Para atingir esses resultados são utilizadas ferramentas como blogs, perfis em redes sociais, ferramentas de email marketing, software de automação de marketing, plataformas de marketing de conteúdo e plataforma de $\mathrm{CR}$. A criação de um relacionamento leva tempo e 
confiança, atributos essenciais para a aplicação do Inbound Marketing. O Inbound Marketing utiliza uma técnica de postagem nas redes sociais de forma que o cliente se sinta atraído a consumir determinado produto ou serviço. Parte-se do pressuposto que o cliente chega a tal decisão por vontade própria, e não por ser conduzido de maneira forçada a buscar tal produto. A palavra-chave é "conquistar" o cliente.

O processo do Inbound Marketing funciona em quatro passos: 1) Atrair: com blog, redes sociais, sites e SEO (Google e outros mecanismos de busca e pesquisa). 2) Conversão: após atrair um público deve-se estimulá-lo a consumir postagens e conteúdos nas redes sociais. 3) Vendas: é nesse momento que o público, atraído e convertido, irá consumir de fato e trará retorno financeiro. 4) Encantamento: é a construção do relacionamento e fidelização dos clientes, é nesse momento que os clientes estão engajados com a marca a ponto de compartilhá-la com outros futuros consumidores em potencial.

Concluído todo o processo, a empresa terá um público alinhado com os interesses e objetivos da empresa. Kotler (2017) diz que o consumidor tende a confiar mais na forma horizontal que vertical. No passado, os consumidores eram facilmente influenciados por campanhas de marketing, mas também buscavam e ouviam autoridades e especialistas.

Entretanto, pesquisas recentes, em diferentes setores, mostram que a maioria dos consumidores acreditam mais no fator social (amigos, família, seguidores do Facebook e do Twitter) do que nas comunicações de marketing.

\subsubsection{FERRAMENTA PDCA}

PDCA: Plan (planejar), Do (executar), Check (checar/controlar) e Act (agir), é uma ferramenta muito utilizada pelos gestores na organização por ser extremamente eficaz no auxílio da tomada de decisões, o que que acelera o processo de identificação de problemas, e, com isso, facilita a resolução de decisões importantes. 
Essa ferramenta também pode ser útil em outros diversos processos dentro de uma empresa, como para a criação de novas propostas e na implementação de novos métodos e ideias, de modo a auxiliar a rotina da organização como um todo.

Conforme Falconi (2009), são nas atividades rotineiras de uma organização que ocorre, não uma parte, mas todos os problemas da empresa, e, por isso, essas atividades precisam ser realizadas de maneira eficaz, precisa e perfeita.

Por isso, e por outras muitas razões, o planejamento, a checagem, o controle e a ação, tornam-se indispensáveis nos processos organizacionais em geral, uma vez que, sem eles, todo o sistema operacional pode entrar em colapso e se tornar um caos.

Para Sousa et al. (2017, p. 123), "a ferramenta PDCA pode auxiliar a empresa para uma produção com menores perdas, utilizando a melhoria contínua como umas das estratégias para garantir a satisfação dos clientes e bom alcance das dimensões da qualidade."

\section{MATERIAIS E MÉTODOS}

Tendo em vista a imensidão de informações, as quais se é possível ter acesso a todo momento, é de suma importância que seja estabelecida uma maneira mais eficiente, compreensível, ágil e transparente de se apresentar todos os conhecimentos encontrados por meio de pesquisas, de modo a realizar o objetivo proposto. O termo que define tal procedimento de organização de dados é Metodologia. Segundo Zanella (2013), este termo se refere ao estudo do método, podendo também ter significados diversificados e distintos.

Formulam-se estratégias diversas de aprendizagem, que apresentam compatibilidade com qualquer perfil de pessoa, principalmente quando citada a figura de um estudante, em que, segundo Freire (2016, p. 58), "se o aprendizado acontece no aluno e na sua velocidade, nada mais interessante que ele controle e realize de modo autônomo seu aprendizado".

RC: 101987

Disponível em:

https://www.nucleodoconhecimento.com.br/administracao/ferramenta-inbound 
Os métodos analisados neste projeto têm como foco a adequação de pontos específicos do estabelecimento Guerreiro's Soluções Gastronômicas, responsável pelo fornecimento de produtos alimentícios de alta qualidade, de modo a adaptar processos e recursos tecnológicos utilizados no ambiente organizacional para algo além das tendências mais atuais do ramo comercial.

\subsection{PROCEDIMENTOS METODOLÓGICOS}

A definição de um procedimento metodológico mostra-se primordial quanto à inicialização de uma pesquisa e aos métodos a serem utilizados. Como ponto de partida, é realizada a análise de cada etapa dos processos, assim como a verificação das avaliações dos meios, e, por fim, se define como será realizada a intervenção na área de Marketing, que representa uma metodologia ativa no ambiente da empresa.

\subsubsection{QUANTO À NATUREZA}

Ao se considerar o objetivo do projeto de intervenção, que busca trazer resultados positivos a curto prazo, prevalece uma natureza de aplicação imediata de modo quali-quantitativo, que combina pesquisa qualitativa e pesquisa quantitativa. Com base nisso, a equipe realizou um levantamento de dados, por meio do qual foi feita a interpretação e análise dos dados, de modo a encontrar uma solução para o problema.

Para Knechtel (2014), a pesquisa quali-quantitativa tem por objetivo interpretar símbolos numéricos e, com isso, descobrir informações de forma quantitativa. Por outro lado, interpreta informações qualitativas mediante observação, interação e interpretação da semântica. Já para Gerhardt; Silveira (2009), a pesquisa qualitativa pouco tem a ver com números e muito a ver com o aprofundamento e conhecimento de determinada organização. 
Portanto, após uma simulação, é feita uma análise quali-quantitativa dos resultados pós-implantação provisória.

\subsubsection{QUANTO AOS FINS}

A pesquisa possui caráter explicativo, pois apresenta uma meta de melhorias imediatas pós implementação de sistemas voltados para o Marketing, e apresenta certeza em relação a mudança acarretada no ambiente organizacional. Para Andrade (2017), a pesquisa explicativa torna-se mais aprofundada que as demais, por sua riqueza de detalhes em entender as causas de determinadas situações. Segundo Leão (2017), a pesquisa explicativa procura entender a realidade das situações e seus porquês.

A pesquisa assume um caráter explicativo devido a necessidade de orientações com relação ao que foi explorado e proposto, pois é de suma importância que a observação do ambiente seja feita do modo que foi imposto pela metodologia.

\subsubsection{QUANTO AOS MEIOS}

Conforme afirma Gil (2008), a pesquisa de campo é realizada por meio de entrevistas em um ambiente e grupo específico, para fins de observação.

A pesquisa de campo é um meio viável de se aplicar o projeto de maneira eficiente, uma vez que a implementação de um novo processo advém da análise dos que já existem. Além disso, também há necessidade de equipamentos para o mesmo.

\subsection{CARACTERÍSTICAS DA EMPRESA}

A Guerreiro's Soluções Gastronômicas é uma empresa que atua no mercado desde 3 de setembro de 2020, inaugurada pelo sócio e chef de cozinha Fábio Guerreiro Leandro, cuja razão social é o seu nome, com o CNPJ: 29.836.725/0001-04, Inscrição Municipal: 40490401 e localizado na Rua Pires do Rio, 556 - Aleixo, Manaus - CEP: 69069-830. Seu comércio busca oferecer gastronomia de alta 
qualidade por um preço mais acessível, e possui o slogan "Comendo bem e barato", que expressa com bastante ênfase o propósito do negócio.

Trata-se de um local com uma área relativamente pequena, com pouco mais de $150 \mathrm{~m}^{2}$, que tem o objetivo de se tornar referência no ramo de alimentação no bairro do Aleixo. O local serve produtos como: sanduíches, batatas e cebolas fritas, grelhados, hot dogs, sobremesas etc. E garante ter qualidade superior à de concorrentes por um preço menor.

O local conta com uma equipe pequena, com um subchefe e dois auxiliares de cozinha, na qual Fábio é chef de cozinha. Conta também com duas pessoas confiáveis para administrar os recursos da empresa. Sendo assim, portanto, uma equipe pequena que visa trabalhar com muita sinergia para melhor atender a todo tipo de público.

\section{RESULTADOS E DISCUSSÕES}

Esta etapa de resultados e discussões se trata da etapa da pesquisa em que evidências serão apontadas por meio da coleta de dados e análises gráficas, para interpretação das informações que confirmam ou refutam hipóteses levantadas ao decorrer do artigo.

Com base nos estudos feitos por meio do diagnóstico organizacional, foi possível obter dados e resultados relacionados a todas as áreas de atuação da empresa Guerreiros Soluções Gastronômicas, nos quais se observou a média de cada área de acordo com seu desempenho funcional e constatou-se que os resultados apontados nesta etapa estão extremamente balanceados, o que permite que a empresa tenha um excelente desempenho no mercado, exceto pela área apontada no setor de Marketing, que se apresenta consideravelmente abaixo da média. 
Gráfico 1 - Medição de desempenho

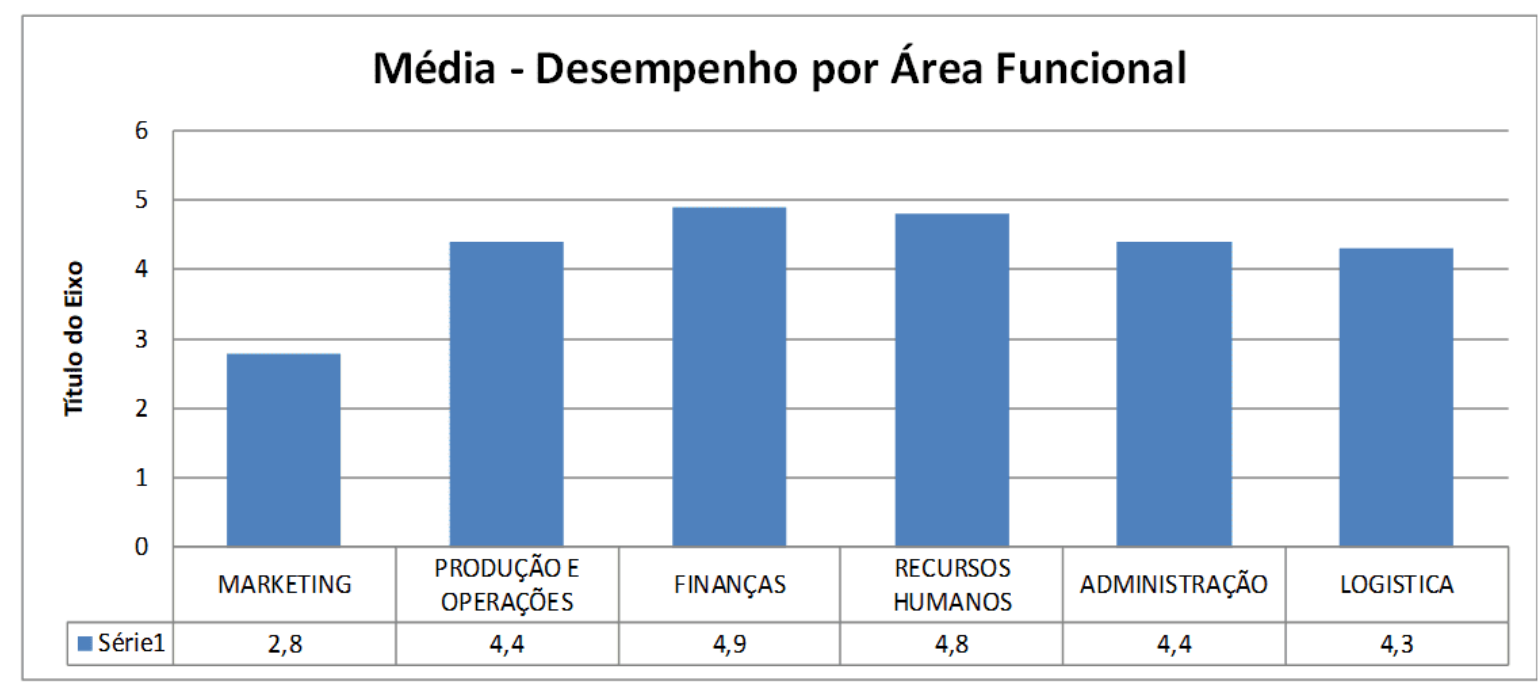

Fonte: Elaborado pelos autores conforme pesquisa de campo

Observou-se que as áreas com desempenho elevados são: Finanças, em primeiro lugar; a área de Recursos Humanos, em segundo lugar; as áreas de Administração e Produção e Operações, em terceiro lugar, com pontuações equivalentes; e área Logística, em quarto lugar. E por fim, a área do Marketing, que comparada às outras áreas, apresentou um desempenho mais crítico.

Com base nesses dados, foi concluído que a área de Marketing necessitava de mais atenção e investimento, assim como um processo de reformulação, por meio de ferramentas adequadas, estratégias planejadas e de profissionais capacitados e especializados.

Quadro 1 - Marketing

ÁREA FUNCIONAL

MARKETING
NÍVEL OU GRAU DE AVALIAÇÃO

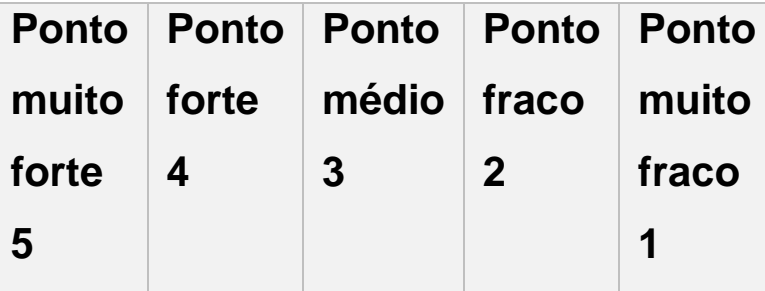

RC: 101987

Disponível em:

https://www.nucleodoconhecimento.com.br/administracao/ferramenta-inbound 


\begin{tabular}{|c|c|c|c|c|c|c|}
\hline 1 & Divulgação via folhetos ou panfletos. & & & & & $x$ \\
\hline 2 & $\begin{array}{l}\text { Uso de páginas ou perfis em mídias } \\
\text { sociais. }\end{array}$ & & & & & $x$ \\
\hline 3 & $\begin{array}{l}\text { Registros em aplicativos de entrega } \\
\text { de produtos alimentícios. }\end{array}$ & $X$ & & & & \\
\hline 4 & $\begin{array}{l}\text { Elaboração de slogan e/ou frases } \\
\text { chamativas. }\end{array}$ & & & $x$ & & \\
\hline 5 & $\begin{array}{l}\text { Utilização de aplicativos de } \\
\text { mensagens como WhatsApp e } \\
\text { Telegram. }\end{array}$ & $X$ & & & & \\
\hline 6 & $\begin{array}{l}\text { Apresentação de dois ou mais } \\
\text { números para recebimento de } \\
\text { ligações. }\end{array}$ & $X$ & & & & \\
\hline 7 & $\begin{array}{l}\text { Especialização para atuar na área } \\
\text { de Marketing. }\end{array}$ & & & & & $x$ \\
\hline 8 & $\begin{array}{l}\text { Área de Marketing e de vendas nos } \\
\text { mesmos contatos. }\end{array}$ & & & & & $x$ \\
\hline 9 & $\begin{array}{l}\text { Ferramentas para facilitar o contato } \\
\text { com o cliente, como contas } \\
\text { comerciais. }\end{array}$ & $X$ & & & & \\
\hline 10 & $\begin{array}{l}\text { Uso de linguagem atrativa para um } \\
\text { público-alvo. }\end{array}$ & & & & & $\mathrm{x}$ \\
\hline \multicolumn{2}{|c|}{ TOTAL $(\Sigma)$} & 20 & 0 & 3 & 0 & 5 \\
\hline \multicolumn{2}{|c|}{ MÉDIA POR GRAU (POR COLUNA) } & 2 & 0 & 0,3 & 0 & 0,5 \\
\hline \multicolumn{2}{|c|}{ DESEMPENHO DA ÁREA $(\Sigma)$ TOTAL } & \multicolumn{5}{|l|}{2,8} \\
\hline
\end{tabular}

Fonte: Elaborado pelos alunos conforme pesquisa

Observa-se na tabela acima os fatores críticos encontrados na área de marketing. Esse baixo desempenho estava vinculado à falta de divulgação do serviço e ausência do gerenciamento das mídias sociais. A inexistência de um profissional da 
área de marketing e de vendas corroboram para os resultados negativos. Assim, levantou-se à seguinte pergunta-problema: a implementação da ferramenta Inboud Marketing pode melhorar as vendas da empresa?

\subsection{PLANEJAMENTO DE AÇÕES}

O Planejamento de ações é uma ferramenta estratégica para a implementação de novas atividades, a fim de melhorar o desempenho do objeto de estudo, por meio da descrição do passo a passo, do tempo e do custo de cada operação empregada. Utiliza-se a ferramenta 5w2h para desenvolver as ações necessárias, com as palavras chaves: "o que”, "quem”, “onde”, “quando”, "por quê", "como” e "quando”.

\subsubsection{IMPLEMENTAÇÃO DO INBOUND MARKETING}

O Inbound Marketing trata-se de uma ferramenta de propaganda menos agressiva que a maioria das ferramentas tradicionais de marketing, porém, muito eficiente.

Segundo o ebook Inbound Marketing (2014), a melhor maneira de se manter na competição que é o mercado atual, é com a utilização do Inbound Marketing, pois, ao invés de distrair seus clientes, você os atrai.

Sendo assim, esta ferramenta utiliza um conjunto de estratégias para atrair o público-alvo.

Quadro 2 - 5w2h - Implementação do Inbound Marketing

IMPLEMENTAÇÃO DO INBOUND MARKETING

O que? Implementação do inbound marketing.

Por quê? Para melhorar o marketing de atração da empresa.

Onde? Guerreiro 's soluções gastronômicas.

Quando? Durante 5 dias.

Quem? Especialista contratado da área.

Como? Atuando na gestão do marketing em mídias sociais. 


\section{Quanto? $\quad \mathrm{R} \$ 1.000,00$}

Fonte: elaborado pelos autores, 2021

O nome Marketing de Atração é o que melhor descreve essa ferramenta, que visa construir uma relação de confiança com o público-alvo e promover a fidelização dos clientes, com investimento significativo em publicações nas mídias sociais.

\subsubsection{BENCHMARKETING}

Benchmarketing é o processo de observar o mercado e analisar as tendências para obter e informações dos concorrentes e consumidores dos seus concorrentes, e com base nos dados adquiridos é possível implementar mudanças positivas e melhorias significativas. O Benchmarketing pode ser aplicado em produtos, serviços ou em um segmento específico de mercado, e pela sua praticidade e baixo orçamento, ele se configura como uma boa opção de marketing

Quadro 3 - 5w2h - Treinamento e capacitação para funcionários

Treinamento e capacitação para funcionários

O que? Ferramenta de Marketing voltada para observação do concorrente.

Por quê? Para captação de informação do concorrente e ajuste de estratégia.

Onde? Guerreiro 's Soluções Gastronômicas.

Quando? Permanente.

Quem? Novo funcionário contratado.

Como? Analisando as propagandas e merchandising dos concorrentes.

Quanto? R $\$ 400,00$

Fonte: elaborado pelos autores, 2021

Uma empresa que investe em qualificação e treinamento, no futuro, adquire bons resultados. Afinal, torna seus profissionais mais capacitados para enfrentar adversidades e lidar com problemas variados. 


\subsubsection{CONSULTORIA VOLTADA PARA O PLANEJAMENTO ESTRATÉGICO}

A consultoria estratégica também é conhecida como consultoria empresarial. Ela visa solucionar problemas internos da organização por meio da busca de profissionais qualificados, que irão fornecer um serviço especializado de forma consideravelmente mais adequada. Este tipo de consultoria empresarial é uma ferramenta necessária para estabelecer a resolução de problemas, pois se utiliza de diversas maneiras e recursos para trazer benefícios e elevar a produtividade, e por esse motivo o investimento nesse tipo de consultoria especializada, em muitos casos, torna-se importante.

Destaca-se o levantamento de informações do como um método de estudo e análise do cenário macroeconômico, considerando-se, nesta análise, os ambientes interno e externo.

Quadro 4 - 5w2h - Consultoria voltada para o planejamento estratégico

Consultoria voltada para o planejamento estratégico

O que? Consultoria voltada para o planejamento estratégico.

Por quê? Para estabelecer objetivos e realizar estudos de mercado.

Onde? Guerreiro 's Soluções Gastronômicas.

Quando? Durante 7 dias

Quem? Com administradores especializados em consultoria empresarial.

Como? Com metodologias e aplicações de ferramentas teóricas.

Quanto? $\mathrm{R} \$ 1.500,00$

Fonte: elaborado pelos alunos, 2021

Os benefícios após o planejamento são extremamente relevantes para a empresa, pois garantem um alinhamento da empresa com os objetivos estabelecidos, maior 
eficiência nas tomadas de decisões e conhecimento apurado da concorrência e dos clientes.

\subsubsection{CONTRATAÇÃO DE UM FUNCIONÁRIO PARA MONITORAMENTO DAS MÍDIAS SOCIAIS}

Para que seja dada a devida atenção às questões online, faz-se necessária a contratação de funcionários capacitados para administrar e controlar as informações envolvidas e relacionadas às mídias sociais, como por exemplo: interagir com os internautas e com os clientes à média, curta e longa distância; administrar os serviços e informações que serão passadas ao cliente; e realizar a manutenção dos perfis da empresa, de modo a criar elementos de marketing e propaganda que chamem a atenção do consumidor e, consequentemente, auxiliem nas vendas e a boa reputação da empresa.

Quadro 5 - 5w2h - Consultoria voltada para o planejamento estratégico

\section{CONTRATAÇÃO DE UM FUNCIONÁRIO}

O que? Contratação de um funcionário para monitoramento das mídias.

Por quê? Pela necessidade de um colaborador dedicado ao serviço.

Onde? Guerreiro 's Soluções Gastronômicas.

Quando? Permanente.

Quem? O novo funcionário.

Como? Contratação por meio de $\mathrm{RH}$.

Quanto? R\$950,00

Fonte: elaborado pelos autores, 2021

Acredita-se que o setor de mídias sociais se torna mais eficiente quando operado por um profissional que se disponibiliza de tempo para dar a devida atenção ao meio digital. 


\subsubsection{AQUISIÇÃO DE ATIVOS PARA MONITORAMENTO DAS MÍDIAS SOCIAIS}

Para melhorar por completo o desempenho do Marketing da empresa, a aquisição de ativos voltados para a administração das mídias sociais é de vital importância para o sucesso.

Quadro 6-5w2h - Aquisição de ativos para o monitoramento das mídias sociais

\begin{tabular}{|c|c|}
\hline $\begin{array}{l}\text { AQUISIÇÃ } \\
\text { SOCIAIS }\end{array}$ & OO DE ATIVOS PARA O MONITORAMENTO DAS MÍDIAS \\
\hline O que? & Aquisição de ativos para o monitoramento das mídias sociais. \\
\hline Por quê? & Para realizar atividade específica do setor. \\
\hline Onde? & Guerreiro 's soluções gastronômicas. \\
\hline Quando? & Permanente. \\
\hline Quem? & Para funcionário designado a trabalhar com o novo equipamento. \\
\hline Como? & Aquisição por meio de uma compra em loja física ou online. \\
\hline Quanto? & $\mathrm{R} \$ 1.500,00$ \\
\hline
\end{tabular}

Fonte: elaborado pelos autores, 2021

Observa-se que uma organização que investe para que a devida atenção seja dada aos seus clientes, por meio digital, consegue refletir bons resultados para sua empresa.

\section{CONSIDERAÇÕES FINAIS}

Por meio da pesquisa e dos estudos detalhados realizados na empresa Guerreiros, pôde-se conhecer mais a respeito de seus departamentos, seu funcionamento, sua equipe, sua estrutura e seus pontos fortes e fracos, e com base nisso foi escolhida uma ferramenta para auxiliar no aprimoramento das áreas problemáticas. Com a 
limitação na área do Marketing e a aplicação da ferramenta Inboud, estimou-se, como apontaram os dados, o aumento nas vendas a superação do concorrente.

Sendo assim, este estudo teve a finalidade de solucionar problemas relacionados ao marketing e apontar soluções para a área mais crítica da empresa. Neste ponto, a pesquisa obteve resultados satisfatórios, uma vez que, por meio do levantamento dos dados visualizados no estudo, foi possível utilizar a ferramenta adequada para a situação. No entanto, se trata de um processo ainda em continuidade, e ainda levará um tempo até que a organização adote, de fato, a ferramenta proposta no artigo presente. Perante essa situação, esperava-se que, após a implementação da ferramenta Inbound, se obtivesse resultados visíveis e que eles se traduzissem em benefícios para a empresa, com o aumento de lucro a partir da melhora das vendas, maior atratividade e fidelização dos clientes.

Com relação a pergunta problema: Como a implementação da ferramenta Inbound Marketing pode melhorar as vendas da empresa? A introdução do Inbound Marketing permite que se construa uma ligação entre colaborador e cliente e que se atinja o seu público-alvo, por meio de mídias sociais e de atrativos proporcionados pela ferramenta de marketing, de modo a trazer melhoras para vendas da empresa. Em conjunto com a introdução da ferramenta Inbound Marketing, também se planejou ações de treinamento e de capacitação dos colaboradores e mudanças estratégicas, apoiadas por uma consultoria externa, além de buscar investir na aquisição de equipamentos e na contratação de profissionais dedicados para gestão das ações de marketing.

Pode-se concluir, por meio de dados específicos das áreas funcionais e gráfico de desempenho, que uma área sozinha pode causar um grande impacto na empresa como um todo, assim como a área de Marketing impacta diretamente nas vendas. Levando isso em conta, foi realizado um processo de análise por meio do suporte estratégico, utilizando o $5 \mathrm{~W} 2 \mathrm{H}$, e então foi proposta a implementação da ferramenta mais adequada para lidar com os problemas da empresa. Portanto, levando em conta este estudo aplicado na organização, foi-se capaz de obter respostas 
referentes a problematização analisada na empresa. Teve-se como base os estudos dos conceitos e das aplicações do Inbound Marketing no mercado, e tendo em vista a análise dos autores sobre as demais áreas organizacionais, que também apresentam um nível de importância elevado, houve incertezas com relação à utilização da ferramenta na empresa abordada.

Entretanto, após identificar a carência de uma área voltada para o Marketing, no ambiente interno, houve, então, a formulação de um acordo entre as ideias apresentadas, de modo a evitar qualquer tipo de conflito ou interferência no andamento da proposta de implementação dos fundamentos do Inbound Marketing. Considerado um dos grandes pilares da área de administração, o Marketing, mesmo atualmente, ainda se apresenta de vital importância para o funcionamento das empresas atuantes no mercado, por entrar em contato direto com o cliente. As novas ramificações dessa área têm se tornado cada vez mais vantajosas de serem exploradas e estudadas, tendo em vista os potenciais resultados que podem ser atingidos.

Com tal informação em mente, as ideias apresentadas no artigo consistiram na utilização do Marketing por meio de ferramentas comuns da tecnologia atual, com o objetivo de impulsionar a divulgação do objeto de estudo e verificar as mudanças obtidas com a aplicação do que foi proposto.

\section{REFERÊNCIAS}

ANDRADE, Maria. Introdução à Metodologia do Trabalho Científico. São Paulo: Atlas, 2017.

ENDEAVOR - Ebook Inbound Marketing: o guia definitivo. Webinsider: 2014. Disponível em < https://endeavor.org.br/inbound-marketing-guia-definitivo/>

FALCONI, Vicente. Gerenciamento pelas Diretrizes. Minas Gerais: INDG Tecnologia e Serviços Ltda, 2004. 
FOX, S; RAINIE, L. (2014). The Web at 25 in the US. Pew Research Center's Internet \& American Life Project. (2014) Disponível em http://www.pewinternet.org/2014/02/27/the-web-at-25-in-the-u-s/.

GERHARDT, Tatiana; SILVEIRA, Denise. Métodos de Pesquisa. Rio Grande do Sul: $\quad$ UFRGS, $2009 . \quad$ Disponível: http://www.ufrgs.br/cursopgdr/downloadsSerie/derad005.pdf

GOMES, Diego; MESQUITA, André. Inbound Marketing 2.0: o futuro do marketing já chegou. Belo Horizonte: 2016.

GIL, Antonio Carlos. Como elaborar projetos de pesquisa. 4. ed. São Paulo: Atlas, 2008.

ISABELLE, Juliana. Marketing estratégico: Orientação para empresas de artigos evangélicos. Curitiba: 2009.

KLOTER, Philip. Marketing para o século XXI. Rio de Janeiro: Ediouro, 2009.

KLOTER, Philip. Marketing 4.0 do tradicional ao digital. Rio de Janeiro: GMT Editores Ltda, 2017.

KAPLAN, Andreas; HAENLEIN, Michael. Social Media: back to the roots and back to the future. 2012. (2012).

KNECHTEL; Maria. Metodologia da pesquisa em educação: uma abordagem teórico-prática dialogada. Curitiba: Intersaberes, 2014.

LAMBIN, Jean. Marketing Estratégico. Lisboa: MacGraw-Hill, 2000.

LEÃO; Lourdes. Metodologia do Estudo e Pesquisa: facilitando a vida dos estudantes, professores e pesquisadores. Rio de Janeiro: Vozes, 2017. 
MARTINS, Daniela. Marketing Digital. Portugal: FEUP, 2020. Disponível em: https://repositorio-aberto.up.pt/bitstream/10216/59978/1/000143905.pdf

MENDES, Lucas; ALBERTO, José. A evolução do marketing digital: uma estratégia de mercado. Ceará: ENEGEP, 2015. Disponível em: aberto.up.pt/bitstream/10216/59978/1/000143905.pdf

NASCIMENTO, Danielle. Medo e Consumo: os efeitos de sentido da "publicidade de choque". Maceió: UFAL, 2017.

PAULA, Lidiane; SOUZA, Antonio. Revista Episteme Transversalis. v.10, n.1, 2016. Disponível em: < http://revista.ugb.edu.br/index.php/ episteme/article/view/167>.

SIQUEIRA, André. Marketing Digital. São Paulo: Sebrae, 2020.

SANT'ANNA, Armando et al. (org). Propaganda: teoria, técnica e prática. 8. ed. São Paulo: Cengage Learning, 2013.

SANTOS, Adriana; ANDREOLI, Pasquotto. Marketing viral: um estudo de caso de três vídeos do banco Itaú que se tornaram virais de sucesso. 2015.

SOUSA; Saymon et al. (org). A importância da ferramenta PDCA no processo industrial portuário: estudo de caso em um carregador de navios. São Paulo: 2017.

ZANELLA; Liane. Metodologia de Pesquisa. Florianópolis: UFSC, 2013.

Enviado: Outubro, 2021.

Aprovado: Novembro, 2021. 